\title{
Tracheal stent placement provides opportunity for subsequent anti-cancer therapy for cancer patients with malignant respiratory complications
}

\author{
Gang Ma", Rong Yang", Baochun Gu, Daofeng Wang, Wei Liao, Xinrong He \\ Intensive Care Unit Department, Sun Yat-sen University Cancer Center, Guangzhou, China \\ Contributions: (I) Conception and design: G Ma; (II) Administrative support: G Ma; (III) Provision of study materials or patients: B Gu, D Wang, W \\ Liao; (IV) Collection and assembly of data: R Yang; (V) Data analysis and interpretation: R Yang, X He; (VI) Manuscript writing: All authors; (VII) \\ Final approval of manuscript: All authors. \\ "These authors contributed equally to this work. \\ Correspondence to: Gang Ma. Intensive Care Unit Department, Sun Yat-sen University Cancer Center, 651 Dongfeng East Road, Guangzhou, China. \\ Email: magang@sysucc.org.cn.
}

\begin{abstract}
Background Critically ill patients with severe acute dyspnea due to malignant tracheal stenosis or tracheoesophageal fistula often need advanced respiratory support. Tracheal stenting is an important palliative treatment of such patients. This study retrospectively analyzes the efficacy and outcomes of airway stenting in patients with tracheal stenosis or tracheoesophageal fistula.

Methods: Patients underwent stenting from 2005 to 2018 in a single center were reviewed. Ninety-seven patients with malignant tracheal stenosis and/or tracheoesophageal fistula who underwent stenting were analyzed, all these patients had poor respiratory status.

Results: The median survival time of patients after stent placement was 119 days. Forty-five patients were treated with anti-tumor therapy after placing the stent. Discharged intensive care unit (ICU) within 3 days and postoperative antitumor treatment were independent predictors for the survival time after tracheal stenting $(\mathrm{P}<0.05)$.
\end{abstract}

Conclusions: Tracheal stent implantation played an important role for additional anti-cancer treatment.

Koywords: Tracheal stenosis; tracheoesophageal fistula; tracheal stenting; tumor support therapy

Submitted Oct 25, 2019. Accepted for publication Aug 19, 2020.

doi: 10.21037/apm-19-419

View this article at: http://dx.doi.org/10.21037/apm-19-419

\section{Introduction}

Tracheal stenosis and tracheoesophageal fistula are two malignant respiratory complications in patients with cancer. Tracheal stenosis is caused by compression of endogenous or exogenous tumors (1), while tracheoesophageal fistula is one of the serious complications of esophageal cancer (2). Both tracheal stenosis and tracheoesophageal fistula cause different degrees of dyspnea, even life-threatening injuries in severe cases. It is reported that there are about 80,000 cases of malignant central tracheal stenosis every year in United States (3). Tracheal stenosis mainly divided into four types: cavity type, external cavity type, tube wall type and mixed type. The degree of a stenosis over $75 \%$ is called a severe stenosis. The overall 5 -year survival rate of esophageal cancer in United States is around $15-20 \%$ (4). Even worse, for the quality of life of patients with tracheoesophageal fistula is extremely poor, it often accelerates death of patients (5). Thus, prompt treatment is required. However, the options for treating patients with malignant respiratory complications are frequently difficult due to poor general status of these patients. Previously, some patients were treated with chemotherapy, microwave or photodynamic therapy $(2,5-8)$, but regarding time and 
effect, results were not satisfactory, even directly lead to death of some patients. In comparison, tracheal stent implantation is a relatively safe and effective method for managing tracheal stenosis and tracheoesophageal fistula $(2,5,9-11)$. As in previous studies, the morbidity rate of tracheal stenting for malignant tracheal stenosis was $20 \%$ to $42 \%$, and the mortality rate was reportedly $8 \%(12-14)$. The 6-month survival rate after interventional treatment among patients with malignant tracheal stenosis was reportedly $20 \%$ (9). In order to further understand these malignant respiratory complications and to provide evidence for future treatment, we retrospectively studied patients who underwent tracheal stent implantation in our hospital from 2005 to 2018. All patients had poor respiratory status due to tracheal stenosis or tracheoesophageal fistula. The study aims to discuss prognostic factors and postoperative outcome.

\section{Methods}

\section{Patients}

We retrospectively analyzed medical records of 97 patients with complete data who underwent tracheal stent implantation at the Sun Yat-sen University Cancer Center, Guangzhou, China, during the period 2005-2018. Follow-up information was collected from the medical records or via telephone contacts with staffs of the hospital. Each patient has signed the informed consent for stent placement. This study was conducted in accordance with the Declaration of Helsinki (as revised in 2013). According to the Research Ethics Committee of the Sun Yat-sen University Cancer Center in 2018, this retrospective study does not need to undergo ethical review or provide an ethics statement because the research object is patient information, not the patient itself. And individual consent for this retrospective analysis was waived.

\section{Stents and placement technique}

Respiratory function was judged by preoperative examination and blood gas analysis. While the location, length and degree of stenosis were judged by preoperative chest X-ray, computed tomography (CT) and fiberoptic bronchoscopy, deciding the type of stent and the best position of stent placement. The stent was made of shape memory nitinol, membrane or non-membrane (Bonastent, Korea, Bostin Scientific, Ireland or micro-tech, China).
The patients underwent tracheal stent implantation in the interventional operating room. After conscious sedation, fiberoptic bronchoscopy was used to locate the upper part of the lesion, paraffin oil was applied to reduce friction. Metal lines were attached to the corresponding body surface to mark the lesion. If fiberoptic bronchoscopy could pass through the narrowing of the lesion, the corresponding surface metal marks were made under the lesion in the same way. The fiberoptic bronchoscope was used to insert the guide wire and pass it through the narrow area, then withdrawn the fiberoptic bronchoscope. Thereafter, guided by the guide wire, the stent releaser was implanted into the airway. With the assistance of X-ray fluoroscopy, the releaser was placed in the corresponding position according to the body surface markers, releasing the stent. After that, the releaser and the guide wire were withdrawn, then location and extent of dilatation of the stent were observed by fiberoptic bronchoscopy immediately $(5,15,16)$. Chest $\mathrm{X}$-ray or CT scan was performed on the first day after operation to inspect if atelectasis had recurred. Fiberoptic bronchoscopy was performed to examine the location and extent of dilatation of the stent.

\section{Data analysis}

Statistical analysis was performed using a statistical software, SPSS 17.0 (Chicago, IL, USA). Multivariate analysis was performed using Cox regression analysis. Survival curves were calculated by the Kaplan-Meier method and compared using the log-rank test. A value of $\mathrm{P}<0.05$ was considered significant.

\section{Results}

\section{Patients characteristics and clinical outcomes}

Among the 97 patients, 73 (75.3\%) were male and 24 (24.7\%) were female, average aged 57.1 (range, 15-83) years old, and $64(66.0 \%)$ had died by the end of the followup period. The patient characteristics are shown in Table 1. As for the location of stenosis, 78 patients had tracheal stenosis, 18 had left or right bronchial stenosis, and 8 had mixed stenosis. In addition, 6 patients placed two stents at the same time, while 7 patients placed twice. In the Cox analysis of potential prognostic indicators of overall survival (OS), surgical treatment was significant associated with the OS of these patients $[\mathrm{P}=0.006$; hazard ratio $(\mathrm{HR})=0.499$; $95 \%$ confidence interval $(\mathrm{CI})=0.303-0.823]$ (Table 2). 
Table 1 Baseline characteristics

\begin{tabular}{|c|c|}
\hline Variables & Total $(n=97)$ \\
\hline Age (years) & 57.05 \\
\hline \multicolumn{2}{|l|}{ Gender } \\
\hline Female & 24 \\
\hline Male & 73 \\
\hline \multicolumn{2}{|l|}{ Clinical staging } \\
\hline I-II & 11 \\
\hline III-IV & 46 \\
\hline \multicolumn{2}{|l|}{ Primary disease } \\
\hline \multicolumn{2}{|l|}{ Lung cancer } \\
\hline Squamous carcinoma & 9 \\
\hline Adenocarcinoma & 5 \\
\hline SCLC & 2 \\
\hline Non-SCLC & 1 \\
\hline Sarcomatoid carcinoma & 1 \\
\hline Tracheal carcinoma & 7 \\
\hline Esophageal cancer & 54 \\
\hline Mediastinal tumor & 8 \\
\hline \multicolumn{2}{|l|}{ Other } \\
\hline Nasopharyngeal carcinoma & 1 \\
\hline Gastric cancer & 1 \\
\hline Colon cancer & 1 \\
\hline Larynx cancer & 1 \\
\hline Thyroid carcinoma & 1 \\
\hline Osteosarcoma & 1 \\
\hline Neuroendocrine tumor & 1 \\
\hline No pathology & 2 \\
\hline \multicolumn{2}{|l|}{ Classification } \\
\hline Tracheobronchial fistula & 19 \\
\hline Tracheal stricture & 78 \\
\hline Surgery & 48 \\
\hline Preoperative chemoradiotherapy & 55 \\
\hline Postoperative treatment & 45 \\
\hline Tracheal intubation & 25 \\
\hline \multicolumn{2}{|l|}{ Prognosis } \\
\hline Live & 33 \\
\hline Death & 64 \\
\hline
\end{tabular}

SCLC, small cell lung cancer.
We further calculated the survival time of patients after stent therapy. Patients who had improved respiratory function after tracheal stent implantation and successfully transferred out of intensive care unit (ICU) within 3 days were labeled as one group. In other words, these patients were those who had no complications after tracheal stent implantation. In the univariate analysis of potential prognostic indicators of survival time after tracheal stenting, infection $(\mathrm{P}=0.042 ; \mathrm{HR}=1.962 ; 95 \% \mathrm{CI}, 1.024-3.757$, Table 3), discharged ICU within 3 days $(\mathrm{P}=0.000$; HR $=0.285 ; 95 \% \mathrm{CI}, 0.157-0.519)$ and postoperative antitumor treatment $(\mathrm{P}=0.000 ; \mathrm{HR}=0.362 ; 95 \% \mathrm{CI}, 0.216-0.606)$ were significant prognostic indicators for the survival time after tracheal stenting of patients. After adjusting for the listed key clinical prognostic factors, using a multivariate Cox regression analysis discharged ICU within 3 days $(\mathrm{P}=0.002 ; \mathrm{HR}=0.268 ; 95 \% \mathrm{CI}, 0.114-0.625)$ and postoperative antitumor treatment $(\mathrm{P}=0.002 ; \mathrm{HR}=0.431$; $95 \%$ CI, 0.251-0.742) were independent predictors for the survival time after tracheal stenting of patients.

In this study, the median survival time of patients after stent placement was 119 days, and the median follow-up period was 124 days. Being stented, the median survival time for patients who continued antitumor therapy was 215 days (95\% CI, 81.130-348.870), compared with 63 days (95\% CI, 43.103-82.897) for patients without succeeding antitumor therapy. Simultaneously, the time for patients who discharged ICU within 3 days was 172 days (95\% CI, 103.202-240.798), compared with 48 days (95\% CI, 13.239-82.761) for patients who did not. Continued antitumor therapy group and the discharged ICU within 3 days group showed favorable survival time after tracheal stenting $(\mathrm{P}=0.000$, Figure 1). Overall, patients discharged ICU within 3 days usually have no obvious complications and their respiratory function has been significantly improved, thus providing an opportunity for follow-up treatment.

\section{Postoperative improvement and outcome}

From the chest X-ray or CT, we clearly see the tracheal stenosis has expanded, pulmonary ventilation function was improved (Figure 2), bronchoscopy showed smooth airway and good expansion (Figure 3). Among these patients, 76 patients were successfully transferred out of the ICU within 3 days after tracheal stent placement, the rest 21 cases (21.6\%) failed to turn out ICU in time because of various 
Table 2 Univariate Cox regression analyses for the OS of patients

\begin{tabular}{lll}
\hline Variables & $\mathrm{HR}(95 \% \mathrm{Cl})$ & $\mathrm{P}$ value \\
\hline Age $(<60 / \geq 60)$ & $1.345(0.818-2.212)$ & 0.243 \\
Gender (female/male) & $1.448(0.800-2.621)$ & 0.222 \\
Clinical staging (I-II/IIIIV) & $1.462(0.640-3.343)$ & 0.368 \\
Surgery (yes/no) & $0.499(0.303-0.823)$ & $0.006^{\star}$ \\
Preoperative chemoradiotherapy & $0.706(0.418-1.191)$ & 0.192 \\
Narrow position & $0.758(0.385-1.495)$ & 0.424 \\
Primary disease & $0.624(0.375-1.038)$ & 0.070 \\
Postoperative treatment & $0.805(0.490-1.322)$ & 0.391 \\
\hline
\end{tabular}

*, $\mathrm{P}<0.05$; determined by Pearson $\chi^{2}$ test and Fisher's exact test. OS, overall survival; HR, hazard ratio; Cl, confidence interval.

Table 3 Univariate and multivariate Cox regression analyses for patients after tracheal stent implantation

\begin{tabular}{|c|c|c|c|c|}
\hline Variables & \multicolumn{2}{|c|}{ Univariate analysis } & \multicolumn{2}{|c|}{ Multivariate analysis } \\
\hline Age $(<60 / \geq 60)$ & $1.442(0.875-2.376)$ & 0.151 & & \\
\hline Gender (female/male) & $1.508(0.832-2.734)$ & 0.176 & & \\
\hline Clinical staging (I-II/III-IV) & $1.094(0.480-2.495)$ & 0.830 & & \\
\hline Preoperative chemoradiotherapy & $1.606(0.957-2.697)$ & 0.073 & & \\
\hline Narrow position & $0.574(0.291-1.131)$ & 0.109 & & \\
\hline Trachea cannula & $0.710(0.405-1.244)$ & 0.231 & & \\
\hline Infect & $1.962(1.024-3.757)$ & $0.042^{*}$ & $0.584(0.235-1.452)$ & 0.247 \\
\hline
\end{tabular}

*, significant difference. HR, hazard ratio; $\mathrm{Cl}$, confidence interval.

factors (Table 4). Among these patients, 1 case was aspiration pneumonia due to aspirated by mistake, 2 cases were blocked by sputum, 2 cases were bleeding, 15 cases were uncontrolled infection, 2 cases were not well dilated, and 1 case failed because of stent prolapse. Forty-five patients were treated with antitumor therapy after placing the stent among these patients.

\section{Discussion}

Tracheal stenosis and tracheoesophageal fistula are important causes of dyspnea caused by tumors that are difficult to be corrected by conventional treatment $(2,3)$.
Tracheal stenosis caused by tumor recurrence or metastasis usually leads to severe dyspnea (16). Clinical symptoms of tracheal stenosis accompanied obvious inspiratory trident sign, life quality of patients decrease in varying degrees (17). The time from onset to dyspnea is often very short, thus respiratory failure caused by tracheal stenosis has become the primary problem to be solved. Treatments of tracheal stenosis include balloon dilatation, electric cautery, argon knife, laser ablation, cryotherapy, intraluminal radiotherapy and stent implantation $(6,8,9,18)$. Compared with various treatments, tracheal stent relieve various types of tracheal stenosis quickly and effectively, with fewer complications $(1,6,8,18,19)$. Tracheoesophageal fistula is a life- 


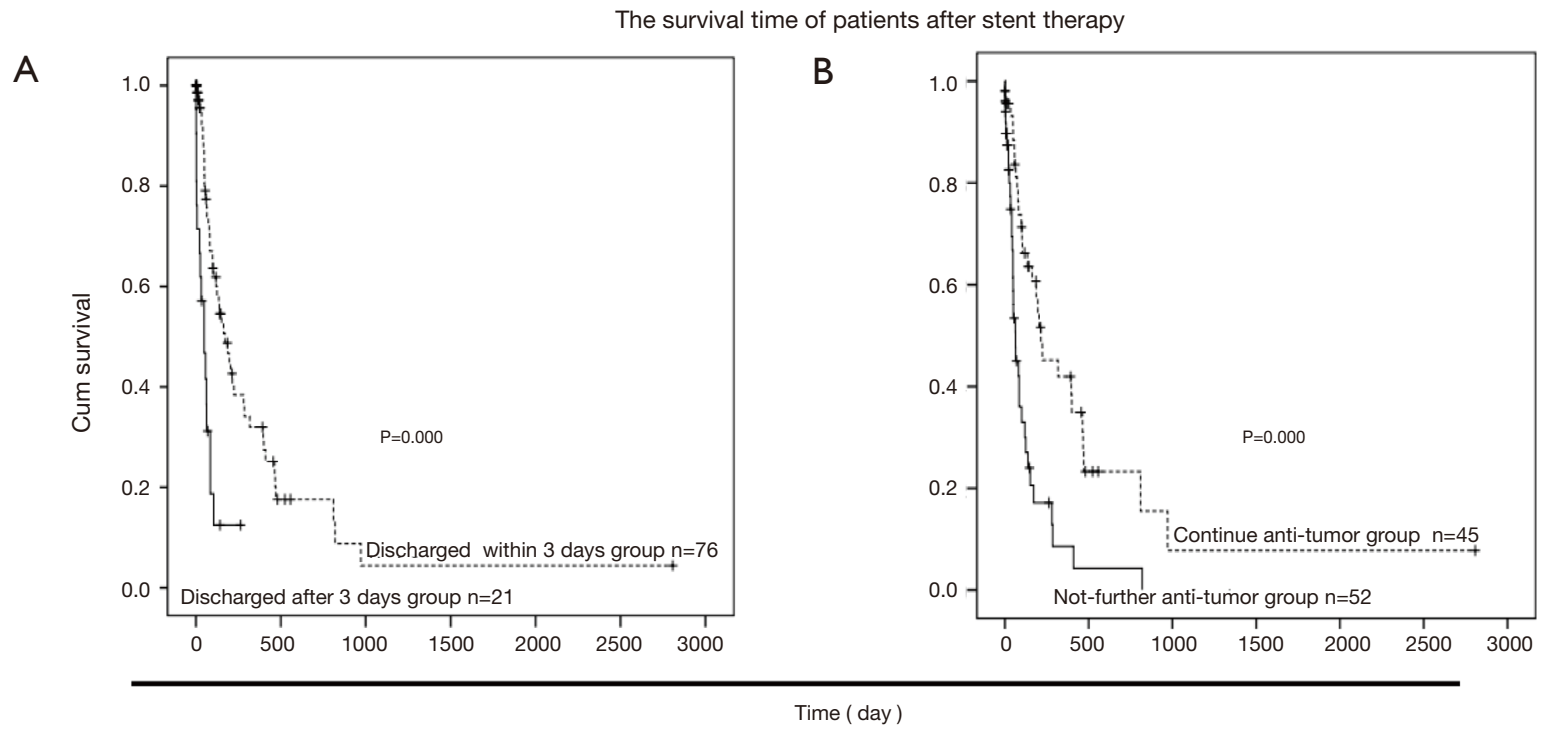

Figure 1 The prognostic values of the length of hospitalization and postoperative anti-tumor treatment in patients. (A,B) The Cox regression analysis curves of patients in this study.

threatening complication of esophageal cancer, it is usually characterized by dyspnea, fever, pulmonary infection, and empyema in severe cases $(2,4,5,20)$. Patients with tracheoesophageal fistula require higher breathing support, such as high-flow oxygen therapy and even ventilatorassisted ventilation, adequate drainage, anti-infection and other adjuvant treatment $(20,21)$. Covering fistula with membranous tracheal stent are effective ways to relieve the pain of patients $(22,23)$. Zhou et al. and other studies also shown tracheal stenting can be reasonable solutions in tracheoesophageal fistulas $(2,5,24)$.

There are few studies on tracheal stent, and the relevant guidelines are not complete. Oki et al. retrospectively investigated the clinical data of 21 small cell lung cancer (SCLC) patients performed tracheal stenting with tracheal stenosis. The median post-procedural survival was 47 days. In univariate and multivariate analyses, the performance of post-procedural tumor-specific therapy, serum lactate dehydrogenase (LDH) levels and the location of stenotic lesions were associated with the survival duration (25). Oki et al. also studied patients with malignant tracheal stenosis who had undergone emergency intubation prior to tracheal stent placement from 2005 to 2015 . The median survival after stenting was 198 days. The Kaplan-Meier method showed that the survival time was significantly prolonged in patients who had received chemotherapy and/or radiation therapy after stenting (11). Twenty-one patients underwent tracheal stenting who had advanced cancer in a prospective study by Nagano et al., the mean survival period after stenting was 85.2 days. In multivariate analysis, PS before tracheal stenting was identified as possible predictor of prognosis after stenting, but postoperative radiotherapy and chemotherapy was not (26). From the above research data, we can find that these diseases are progressing rapidly and have poor prognosis, so urgent airway intervention is necessary to gain time.

Unlike other studies in which lung cancer is the primary cause, in our research, the primary cause was esophageal cancer $(55.7 \%)$, followed with lung cancer, tracheal cancer, mediastinal tumors, metastases and other cancers. Patients with symptoms of tracheal stenosis often had more than $75 \%$ of the tracheal stenosis, reaching severe stenosis. Oncologists pointed out that the patient's basic condition was too poor for anti-tumor treatments, further treatment should be considered only after relieving tracheal stenosis and improving respiratory function. In this case, the patient's basic condition was unable to tolerate other treatments, tracheal stenting was the best choice $(27,28)$.

Tracheoesophageal fistula and tumor metastasis were very common in esophageal cancer. Assisted with symptomatic treatment like anti-infection, most patients with tracheoesophageal fistula sealed successfully by membranous tracheal stents, while dyspnea was significantly improved $(2,4,5,21)$. Stent implantation is suitable for treatment of 


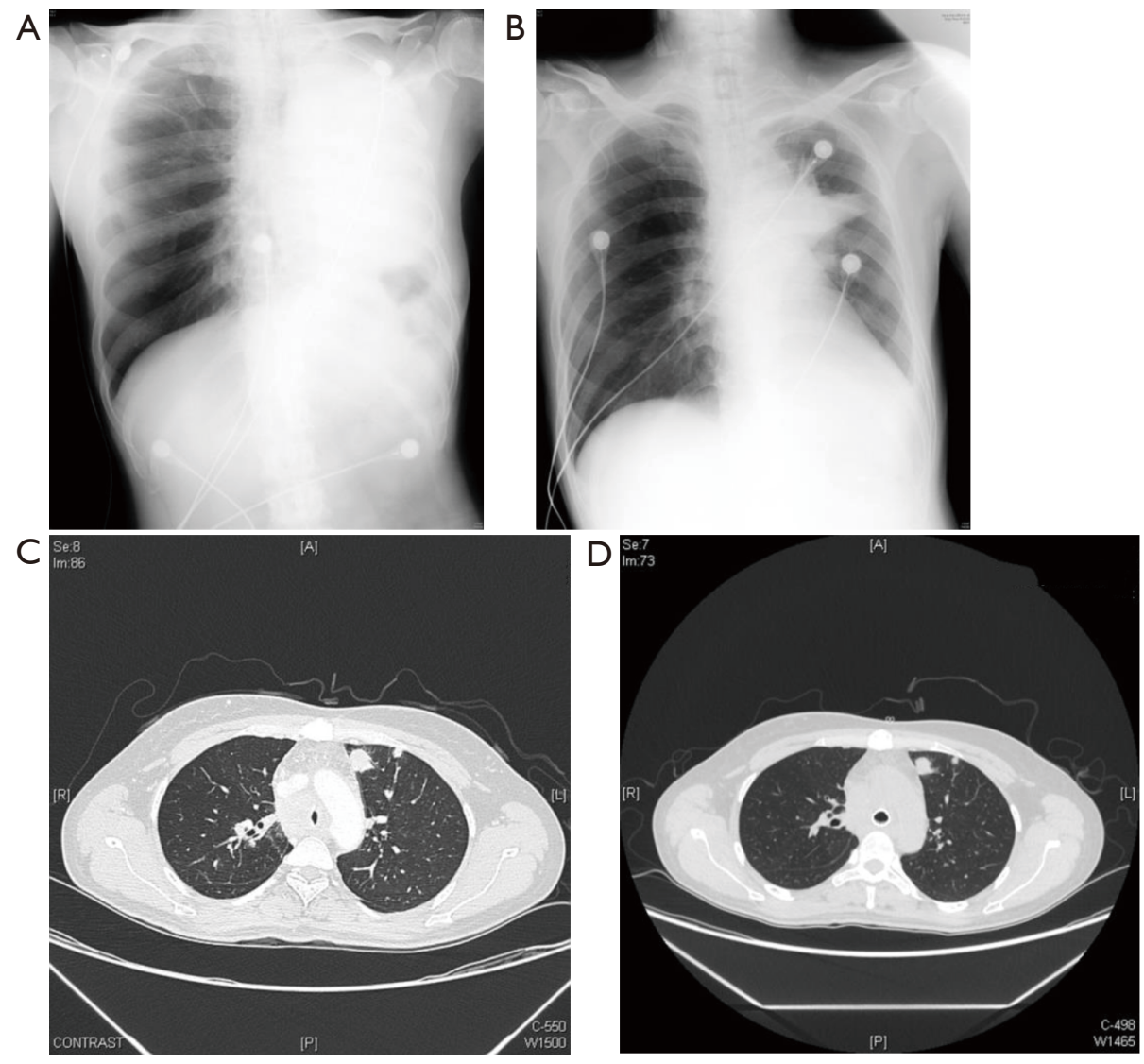

Figure 2 Preoperative and postoperative imaging findings of tracheal stent placement. (A) X-ray films obtained before stent placement shows complete obstruction of the left main bronchus with total collapse of the left lung; (B) X-ray films obtained after tracheal stent implantation shows successful stent expansion and adequate ventilation in the left lung; (C) computed tomography (CT) shows stenosis of the main bronchus, and the degree of stenosis is more than $75 \%$; (D) CT shows that stent is successfully expanded after tracheal stent implantation.
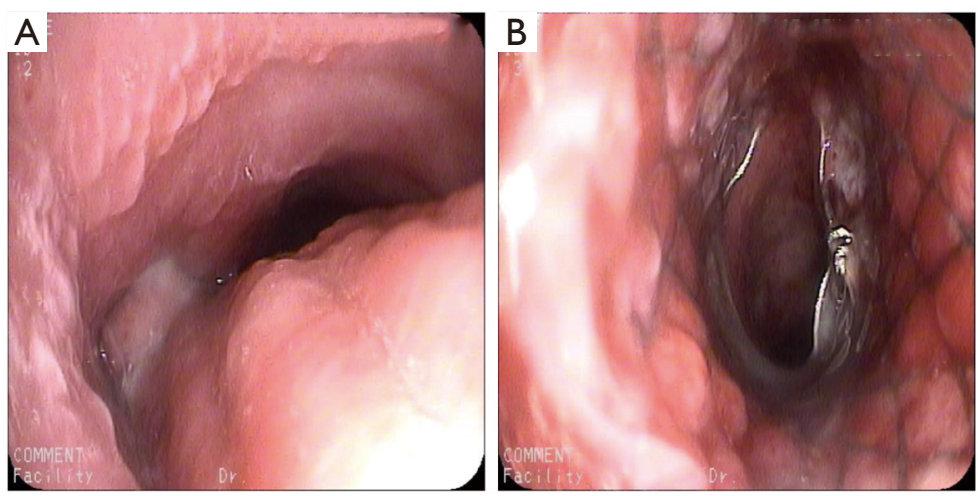

Figure 3 Preoperative and postoperative fiberoptic bronchoscopy findings of tracheal stent placement. (A) Fiberoptic bronchoscopy shows that the patient has main bronchial endobronchial airway tumor; (B) fiberoptic bronchoscopy shows that tracheal stenosis has been relieved. 
Table 4 Complications after tracheal stent implantation

\begin{tabular}{ll}
\hline Complications & Number of cases \\
\hline Aspiration & 1 \\
Expectoration difficulties & 2 \\
Bleeding & 2 \\
Infection & 15 \\
Poor expansion & 2 \\
Stent prolapse & 1 \\
\hline
\end{tabular}

various types of tracheal stenosis or fistula $(29,30)$. In this study, the survival time of 45 patients treated with antitumor therapy after placing stent prolonged significantly. Patients with tracheal stenosis or tracheoesophageal fistula did not lose the opportunity to fight tumors, because stent implantation rapidly and significantly improved dyspnea, improved the quality of life of patients, and won time for follow-up anti-tumor treatment. In particular, whether the patient discharged within 3 days successfully is an independent risk factor in this study. Meanwhile, the key point of this factor is the improvement of respiratory function and evaluate subsequent anti-tumor treatment. According to our observation, severe complications of stent implantation are rare, and satisfactory results can be achieved after treatment. In our study, the morbidity of complications after stent implantation was $21.6 \%$. Therefore, the greatest significance of tracheal stent implantation is to improve the quality of life of patients in a timely manner, and provide opportunity for succeeding anti-cancer treatment.

\section{Acknowledgments}

Funding: None.

\section{Footnote}

Data Sharing Statement: Available at http://dx.doi. org/10.21037/apm-19-419. The authenticity of this article has been validated by uploading the key raw data onto the Research Data Deposit public platform (www. researchdata.org.cn), with the approval RDD number as RDDA2020001457.

Conflicts of Interest: All authors have completed the ICMJE uniform disclosure form (available at http://dx.doi. org/10.21037/apm-19-419). The authors have no conflicts of interest to declare.

Ethical Statement: The authors are accountable for all aspects of the work in ensuring that questions related to the accuracy or integrity of any part of the work are appropriately investigated and resolved. This study was conducted in accordance with the Declaration of Helsinki (as revised in 2013). According to the Research Ethics Committee of the Sun Yat-sen University Cancer Center in 2018, this retrospective study does not need to undergo ethical review or provide an ethics statement because the research object is patient information, not the patient itself. And individual consent for this retrospective analysis was waived.

Open Access Statement: This is an Open Access article distributed in accordance with the Creative Commons Attribution-NonCommercial-NoDerivs 4.0 International License (CC BY-NC-ND 4.0), which permits the noncommercial replication and distribution of the article with the strict proviso that no changes or edits are made and the original work is properly cited (including links to both the formal publication through the relevant DOI and the license). See: https://creativecommons.org/licenses/by-nc-nd/4.0/.

\section{References}

1. Ost DE, Ernst A, Grosu HB, et al. Therapeutic bronchoscopy for malignant central airway obstruction: success rates and impact on dyspnea and quality of life. Chest 2015;147:1282-98.

2. Enzinger PC, Mayer RJ. Esophageal cancer. N Engl J Med 2003;349:2241-52.

3. Murgu SD, Egressy K, Laxmanan B, et al. Central airway obstruction: benign strictures, tracheobronchomalacia, and malignancy-related obstruction. Chest 2016;150:426-41.

4. Short MW, Burgers KG, Fry VT. Esophageal cancer. Am Fam Physician 2017;95:22-8.

5. Zhou C, Hu Y, Xiao Y, et al. Current treatment of tracheoesophageal fistula. Ther Adv Respir Dis 2017;11:173-80.

6. Mostafa BE, El Fiky L, El Sharnoubi M. Non-intubation traumatic laryngotracheal stenosis: management policies and results. Eur Arch Otorhinolaryngol 2006;263:632-6.

7. Wassermann K, Mathen F, Edmund Eckel H. Malignant laryngotracheal obstruction: a way to treat serial stenoses of the upper airways. Ann Thorac Surg 2000;70:1197-201. 
8. Ciccone AM, De Giacomo T, Venuta F, et al. Operative and non-operative treatment of benign subglottic laryngotracheal stenosis. Eur J Cardiothorac Surg 2004;26:818-22.

9. Chhajed PN, Somandin S, Baty F, et al. Therapeutic bronchoscopy for malignant airway stenoses: choice of modality and survival. J Cancer Res Ther 2010;6:204-9.

10. Rochet N, Hauswald H, Schmaus M, et al. Safety and efficacy of thoracic external beam radiotherapy after airway stenting in malignant airway obstruction. Int J Radiat Oncol Biol Phys 2012;83:e129-35.

11. Oki M, Saka H, Hori K. Airway stenting in patients requiring intubation due to malignant airway stenosis: a 10-year experience. J Thorac Dis 2017;9:3154-60.

12. Bolliger CT, Mathur PN, Beamis JF, et al. ERS/ATS statement on interventional pulmonology. European Respiratory Society/American Thoracic Society. Eur Respir J 2002;19:356-73.

13. Chin CS, Litle V, Yun J, et al. Airway stents. Ann Thorac Surg 2008;85:S792-6.

14. Saji H, Furukawa K, Tsutsui H, et al. Outcomes of airway stenting for advanced lung cancer with central airway obstruction. Interact Cardiovasc Thorac Surg 2010;11:425-8.

15. Furukawa K, Ishida J, Yamaguchi G, et al. The role of airway stent placement in the management of tracheobronchial stenosis caused by inoperable advanced lung cancer. Surg Today 2010;40:315-20.

16. Tsukioka T, Takahama M, Nakajima R, et al. Sequential stenting for extensive malignant airway stenosis. Ann Thorac Cardiovasc Surg 2015;21:114-8.

17. Jeon K, Kim H, Yu CM, et al. Rigid bronchoscopic intervention in patients with respiratory failure caused by malignant central airway obstruction. J Thorac Oncol 2006;1:319-23.

18. Duncavage JA, Koriwchak MJ. Open surgical techniques for laryngotracheal stenosis. Otolaryngol Clin North Am 1995;28:785-95.

19. Özgül MA, Çetinkaya E, Seyhan EC, et al. Airway stents: a retrospective evaluation of indications, results and

Cite this article as: Ma G, Yang R, Gu B, Wang D, Liao W, He X. Tracheal stent placement provides opportunity for subsequent anti-cancer therapy for cancer patients with malignant respiratory complications. Ann Palliat Med 2021;10(2):1042-1049. doi: 10.21037/apm-19-419 complications in our 10-year experience. Tuberk Toraks 2019;67:272-84.

20. Martini N, Goodner JT, D'Angio GJ, et al. Tracheoesophageal fistula due to cancer. J Thorac Cardiovasc Surg 1970;59:319-24.

21. Morgan RA, Ellul JP, Denton ER, et al. Malignant esophageal fistulas and perforations: management with plastic-covered metallic endoprostheses. Radiology 1997;204:527-32.

22. Chaaban S, Simoff M, Ray C, et al. Posterior tracheal laceration treated with a stent. Ann Am Thorac Soc 2017;14:1224-26.

23. Cunnane M, Patil S, Sothinathan R, et al. Using a tracheal stent for conservative management of speaking valveassociated tracheo-oesophageal fistula. Clin Otolaryngol 2018;43:770-71.

24. Dumon JF. A dedicated tracheobronchial stent. Chest 1990;97:328-32.

25. Oki M, Saka H. Airway stenting for patients with airway stenosis because of small cell lung cancer. Clin Respir J 2018;12:2257-63.

26. Nagano H, Kishaba T, Nei Y, et al. Indications of airway stenting for severe central airway obstruction due to advanced cancer. PLoS One 2017;12:e0179795.

27. Hamai Y, Hihara J, Emi M, et al. Airway stenting for malignant respiratory complications in esophageal cancer. Anticancer Res 2012;32:1785-90.

28. Alexander EP, Trachiotis GD, Lipman TO, et al. Evolving management and outcome of esophageal cancer with airway involvement. Ann Thorac Surg 2001;71:1640-4.

29. Takeno A, Masuzawa T, Murakami K, et al. Tracheobronchial airway stenting for airway stenosis due to inoperable advanced esophageal cancers. Gan To Kagaku Ryoho 2018;45:2241-43.

30. Cheng WC, Shen MF, Wu BR, et al. The prognostic predictors of patients with airway involvement due to advanced esophageal cancer after metallic airway stenting using flexible bronchoscopy. J Thorac Dis 2019;11:3929-40. 